\title{
Idiom Taxonomies and Idiom Comprehension: Implications for English Teachers
}

\author{
Noorolhoda Saberian \\ Islamic Azad University, Najafabad Branch, Iran \\ Email: hodasaberian@yahoo.com \\ Zahra Fotovatnia \\ Islamic Azad University, Najafabad Branch, Iran \\ Email: Z_fotovatnia@phu.iaun.ac.ir
}

\begin{abstract}
Idioms are an important part of a language, as they are used to express ideas in a more concise and effective way. Idioms have a considerable role in a foreign language as in the mother tongue. Therefore, their learning and teaching in L2 are worthy of attention and research. This paper intends to define idioms, introduce their different taxonomies, discuss $\mathrm{L} 2$ idiom processing and comprehension, and use the information to endow English teachers with some pedagogical implications.
\end{abstract}

Index Terms-idiom taxonomies, idiom comprehension, literal and figurative meaning, opaque and transparent idioms

\section{INTRODUCTION}

Idioms are an important part of any language and may be said to be an indicator of one's fluency in that language (McDevitt, 1993). Cowie, Mackin, and McCaig (1983), in the general introduction to their groundbreaking work Oxford Dictionary of English Idioms, consider the accurate and appropriate use of idioms as one distinguishing mark of the native command of the language and a reliable measure of the proficiency of foreign learners. There are so common that ignoring them will cause learner numerous problems. Foreign language learners learn not only the grammatical structures and vocabulary of the target language, but the idioms as well to integrate into the culture of the foreign language. Dixon (1994) believes that idioms are essential to successful communication, whether in listening, speaking, reading, or writing. Therefore, there are many reasons why one would think that teaching idioms to L2 learners is a good idea. Over the last few decades, linguists and psycholinguists have developed a number of hypotheses to describe the processing, and comprehension of idioms. Presently, there seems to be no agreed upon model or theory. A better understanding of the way in which idioms are processed and comprehend by L2 learners could lead to more effective ways of teaching them to L2 learners.

\section{DEFINITIONS OF IDIOM}

Several criteria have been suggested in the literature to define idioms. The term "idiom" has been used to encompass a wide variety of different types of multi-word units (MWUs). MWUs are vocabulary items which consist of a sequence of two or more words. These words form a meaningful and inseparable unit. Moon (1997) in her description of idioms, argues that the term "idiom" occurs in the literature with a variety of different meanings. She uses the term in the narrow sense to refer to MWUs which are not the sum of their parts: their meaning cannot be retrieved from the individual meanings of the component words. She describes idioms as high in non-compositionality, infrequent in terms of institutionalization (the degree to which a MWU is conventionalized in the language), and often held to be relatively frozen in terms of fixedness. Similarly, Grant and Bauer (2004) believe that the term MWU encompasses both idioms and open and restricted collocations, but excludes phrasal verbs. Open collocations are the loosest kind of MWU and "core idioms" are the most restricted. Furthermore, some idiomatic strings have both a literal and a non-literal meaning; therefore, contextual clues may be necessary to distinguish whether the MWU has a literal or idiomatic interpretation. Clearly, many different forms of MWUs exist yet there is no generally agreed set of definitions in use. According to the idiom widely-held definition, it is a common form of expression whose meaning of the whole is not determinable given the meanings of its individual constituents. McCarthy and O'Dell (2002) define an idiom as a fixed expression whose meaning is not immediately obvious from looking at the individual words in the idiom. Definitions such as these are abundant; however, they all agree on two common characteristics: (a) idioms have a fixed word order, which implies that they are socially accepted expressions, and (b) it is impossible to guess the meaning from the individual words that make up an idiom. A more practical definition of idioms applicable to language learning is that idioms are "multi-word unites which have to be learned as a whole, along with associated sociolinguistic, cultural and pragmatic rules of use" (Alexander, 1987, p. 178). 


\section{DIFFERENT TAXONOMIES OF IDIOMS}

In previous studies, idioms have been classified in a variety of ways by different researchers based on their semantic, syntax, and function (Grant \& Bauer, 2004). This study, however, describes taxonomies of Nunberg (1978), Cacciari and Glucksberg (1991) and yoshikawa (2008) which seem to be more comprehensive.

\section{A. Nunberg's Taxonomy}

Based on Nunberg's taxonomy (1978) semantic taxonomies have been posited to describe how idioms differ in their compositionality, and how these differences may have implications for process model of idiom comprehension (Titone \& Connine, 1999). Nunberg (1978) proposed a typology for characterizing how literal meanings of idiom components contribute (or do not contribute) to the overall interpretation of idiomatic phrases.

According to this system, idiomatic expressions may be arranged into three different classes: normally decomposable idioms, abnormally decomposable idioms and semantically nondecomposable idioms. Normally decomposable idioms are expressions in which a part of the idiom is used literally (e.g., the question in pop the question). Abnormally decomposable idioms are expressions where the referent of an idiom's parts can be identified metaphorically (e.g., buck in the idiom pass the buck). Finally, semantically nondecomposable idioms fit the traditional definition because the idiom meaning is less likely to be derived compositionally from the words that comprise the string (e.g., chew the fat) (Titone \& Connine, 1999).

\section{B. Cacciari and Glucksberg's Taxonomy}

In taxonomy of idiom compositionality, Cacciari and Glucksberg (1991) classify idioms as opaque, transparent or quasi-metaphorical. Opaque idioms are phrases such as kick the bucket in which there is some degrees of semantic constraint on interpretation of the idiom give the meaning of the component words. In contrast, transparent idioms are phrases in which there is a direct mapping of literal word meanings to idiomatic meanings. For example, spill in the idiom spill the beans, which literally translate to divulge a secret directly maps on to the verb divulge, and the beans directly map a secret. Finally, idioms classified as quasi-metaphorical phrases in which the overall literal meaning of the phrases metaphorically maps onto the idiomatic meaning similar to metaphorical expression, these idioms convey their meaning via allusional content (Glucksberg, 1991) that is, they simultaneously refer to an ideal exemplar of a concept and to the contextually determined referent in a particular communicative situation.

\section{Yoshikawa's Taxonomy}

According to this taxonomy, idioms are classified into five different types: A, B, C1, C2 and D (the last idiom type was added by Saberian, 2011). In this taxonomy, the degree of L1-L2 structural and semantic similarity is taken as the primary criterion in classifying English idioms. An L2 idiom is structurally similar to an L1 idiom if the major content words could be literally translated to L1 and it is semantically similar to an L1 idiom when they share the same central concept, and could be used in the same contexts (pragmatically congruent) (Cedar, 2004). Idiom type A, are English idioms with both structural and semantic similarity to L1 idioms, type B are idioms with "partly" structural similarity and semantic similarity to L1 idioms. On The other hand, idiom type C1, are idioms with structural "similarity" but semantic "dissimilarity" to L1 idioms. Type C2, are idioms with both structural and semantic "dissimilarity" to L1 idioms. While idiom type D, are idioms with structural "dissimilarity" but semantic similarity to L1 idioms. They cannot be translated literally into L1 because literal translation does not make sense in L1, yet their literal translation may give learners clue for guessing the idiomatic meaning.

\section{DIFFERENT MODELS OF L2 IDIOM PROCESSING}

The proposals in L2 idiom processing are different in terms of the status they consider for literal and figurative processing accompanying idiom comprehension. Whereas some researchers have maintained that L2 learners comprehend idioms by direct retrieval of their figurative meanings (Nelson, 1992), others have claimed that L2 learners first process idioms literally and only then access their figurative meanings (Liontas, 2002). Matlock and Heredia (2002) have suggested that the role of literal and figurative meanings in the processing of L2 idioms will be determined by the L2 learner's proficiency in the language. Based on this assumption idiom comprehension at early stages of L2 learning consists of three steps. In the first step, an L2 idiomatic expression is translated into L1. Next, the learner accesses the literal meaning of the expression and attempts to make sense of it. Finally, in the third stage, the figurative meaning is accessed. On the other hand, at more advanced stages of L2 learning, the L2 speaker may process figurative expressions in the same manner as a native speaker, without having to access their literal meanings first. In Dual L2 Idiom Representation Model (DIR Model) is assumed that non-decomposable idioms require an idiom entry, whereas decomposable idioms can be represented via constituent entries and can additionally develop an idiom entry (Abel, 2003). In her study, Abel (2003) has compared the judgment of idiom decomposability between native English speakers and German learners of English. The result showed that non-native speakers rate opaque non-decomposable idioms as decomposable and they attributed meaning to individual constituents of opaque idioms, even if this is not correct. She believes that if decomposable idioms have no idiom entry at the lexical level, conceptual representations are accessed during comprehension. Therefore, the twofold claim of dual representation has not only a lexical but also a conceptual 
level of representation and both constituent and idiom entries co-exist at the lexical level. In another model, Cie'slicka (2006) has proposed that the status of literal and figurative meanings in processing idiomatic expressions will be different for native language speakers and for second language learners. Since L2 learners first become familiar with literal meanings of the second language and after a long time, they encounter their figurative meanings in fixed phrases and since literal meanings are more frequently used than idiomatic ones in an L2 learner's performance, it seems more reasonable to assume that literal meanings have a more salient status than figurative ones in the course of processing idiomatic phrases. In this model, salient meanings can be understood as the meanings, which are activated first and most strongly in the course of language processing in the mental lexicon than those of the less salient meanings. This assumption forms the core of the L2 idiom comprehension model.

\section{RESEARCH ON L2 IDIOM COMPREHENSION}

Many earlier idiom studies mainly involved native speakers of English (e.g. Titone \& Connine, 1994). It was only until recent years that researchers began to pay attention to the learning and processing of L2 idioms. (E.g., Cie ' slicka, 2006; Cooper, 1999; Irujo, 1986; Liontas, 2002). These studies, in general, are concerned with two central issues: the effect of L1 on L2 idiom comprehension and the strategies that learners adopt in comprehending L2 idioms.

Kellerman $(1979,1983)$ studied the relationship between native language (NL) knowledge and interpretation of the figurative use of target language (TL) expressions. His studies showed that L1 plays a role in L2 idiom processing even though L2 learners are less likely to transfer L1 knowledge when they perceive the meaning as figurative. In fact he considered the of strategy of "transfer" of NL items into TL expressions to be an active learner strategy dependent on the learners" "distance" between the NL and the TL and the markedness of the structure in the L1. These two factors integrated might serve to prevent interference where L1 and L2 are typologically different, and also to prevent facilitation of transfer where L1 and L2 are close. Afterwards, Irujo (1986) investigated whether advanced students of English relied on knowledge of their native Spanish in order to comprehend and produce L2 idioms. She divided English idioms into three types in comparison with Spanish. One type was identical in form and meaning with Spanish equivalents, the second type was similar to Spanish equivalents, and the third type was different from Spanish idioms. The data obtained from this study showed that idioms, which were identical in both L1 and L2, were the easiest to comprehend and produce. While, idioms, which were similar in L1 and L2 presented learners with only somewhat more difficulty, but idioms that were completely different in L1 and L2 proved to be the most difficult for learners to comprehend and produce. She concluded that there was both positive and negative L1 knowledge transfer in the case of same or similar idioms when the learners' first language was close to the second language.

Liontas (2002) examined the effect of context on the comprehension and interpretation of idioms in three different languages (French, German\& Spanish). The idioms were selected based on their interlingual similarity. The results revealed that context significantly affected the comprehension of idioms. Context favoured more the comprehension of L2 idioms that were different from L1 than those that were similar or identical to L1, which can reach a high percentage of correct answers even in the no context task.

Yoshikawa (2008) studied the comprehension of English idioms by 175 Japanese college students. They were required to write down the equivalent meanings of 12 English idioms in Japanese. After the data analysis, he classified those idiomatic expressions into 4 groups of $\mathrm{A}, \mathrm{B}, \mathrm{C} 1$ and $\mathrm{C} 2$ based on semantic transparency and concluded that the more semantic similarity between the two languages, the more understandable English idiomatic expressions will be.

\section{TEACHING IDIOMS TO L2 LEARNERS}

Since idioms are figurative expressions that do not mean what they literally state and since they are so frequent in spoken and written discourse, understanding and producing them present L2 learners with a special vocabulary learning problem (cooper, 1999). Therefore, it would appear that for second language learners to become more fluent in the target language, just a good command of grammar and vocabulary is not enough. Idioms reflect the language used daily by the native speakers of the target language. Prodromou (2003) claims that in the past, teachers relied heavily on grammar and dictionaries to help them teach but these were not based on a naturally occurring language. Liontas (2002) argues that idioms should be introduced to learners as early as possible along with other aspects of semantics, pragmatics, sociolinguistic, culture and conventions of discourse. He also claims that idioms should not be separated from other aspects of learning a language. In short, idioms should be integrated into the language curriculum right from the start.

In teaching idioms, Lennon (1998) suggests that since idioms are so semantically opaque, they are well suited to a problem-solving approach in teaching, which can exploit learners' innate cognitive drive to make sense out of their environment, therefore, exercises of a problem solving nature can help learners to discover the metaphors in idiomatic expressions. He also claims that comparison with L1 should be encouraged so that learners can become aware of the differences between the metaphors in the target language and their native language. In fact, a cross-linguistic comparison of English and L1 idioms in terms of their conceptual basis is needed when teaching or learning English idioms. Activities, which compare literal and idiomatic meanings of idioms, will provide a link from the literal words to the non-literal meaning. In addition, as suggested by Charteris-Black (2002), learners should "be made aware of the 
connotations of figurative units in the target language and advised to avoid paraphrasing L2 figurative units with translations from L1 figurative units that ignore these connotations" (p.128). Furthermore, based on Yoshikawa's taxonomy (2008) and Saberian's findings (2011), in L2 instruction, differential attention should be paid to different types of idioms, instead of treating all the idioms in the same way. For example, for L2 idioms that have high transparency for transmitting the true meaning and which have L1 equivalents (idiom type A), comprehension will no longer be a problem and do not require a teaching measure. For L2 idioms which have moderate transparency and partial translation equivalent in L1 (idiom types B \&D), L2 teachers have to provide more teaching measures. For L2 idioms that have false transparency and literal translations, make sense in L1 but denote a different meaning other than the target English idioms (idiom type C1), explicit teaching measure in English class is strongly required. Finally, for L2 idioms which have high opacity and cannot be translated literally into L1 (idiom type C2), teaching measures are not urgently needed. However, in speaking, misunderstanding can be avoided by negotiation between speakers but if English teachers want to avoid interruption and delay in conveying the meaning, they should teach the true meaning of these kinds of idiomatic expressions too.

\section{CONCLUSION}

A quick examination of the second language acquisition literature on idioms reveals an ongoing debate over the way in which idioms are defined and categorized. The fact that a variety of definitions exists illustrates the lack of precise definition of the term "idiom". This paper attempted to clarify the issue of teaching idioms to second language learners through an overview of recent idiom taxonomies and theories in idiom comprehension. Clearly, L2 learners know that idioms are an important feature of the target language and want to learn them. This desire alone supports a strong position for teaching idioms in the L2 classroom. Furthermore, it seems that L2 learners, whose goal is to achieve a near-native mastery of the target language, will be unable to avoid learning at least a few idioms. As a result, by raising teachers' awareness of different idiom taxonomies and effect of structural and semantic similarity/dissimilarity between L1 and L2 idioms on comprehension of L2 idioms, they may alter the way they plan and execute their lessons more effectively and successfully.

\section{REFERENCES}

[1] Abel, B. (2003). English idioms in the first language and second language lexicon: a dual representation approach. Second Language Research, 19(4), 329-358.

[2] Alexander, R. J. (1987). Problems in understanding and teaching idiomaticity in English. Anglistik und englischunterricht, $32(2), 105-122$.

[3] Cacciari, C., \& Glucksberg, S. (1991). Understanding idiomatic expressions: The contribution of word meanings. In simpson G.B., (ed.), Understanding word and sentence. North Holland: Elsevier Science Publishers B.V., 217-240

[4] Cedar, P. (2004). Transferability and translatability of idioms by Thai-speaking learners of English. Unpublished Ph.D. dissertation, Boston University.

[5] Charteris-Black, J. (2002). Second language figurative proficiency: a comparative study of Malay and English. Applied Linguistics, 23, 104-133.

[6] Cie ' slicka, A. (2006). Literal salience in on-line processing of idiomatic expressions by second language learners . Second Language Research, 22(2), 115-144.

[7] Cooper, T.C. (1999). Processing of idioms by L2 learners of English. TESOL Quarterly, 33, (2), 233-262.

[8] Cowie, A. P., Mackin, R., \& McCaig, I. R. (1983). Oxford dictionary of current idiomatic English: Phrase, clause and sentence idioms (vol. 2). Oxford: Oxford University Press.

[9] Dixon, R.J. (1994). Essential Idioms in English. New Jersey: Prentice Hall Regents.

[10] Glucksberg, S. (1991). Beyond literal meaning: The psychology of allusion. Psychological Sciences, 2, 146-152.

[11] Grant, L. \& Bauer, L. (2004). Criteria for re-defining idioms: Are we barking up the wrong tree? Applied Linguistics, 25, 3861.

[12] Irujo, S. (1986) . Don't put your leg in your mouth : Transfer in the acquisition of idioms in a second language. TESOL Quarterly, 20(2), 287-304.

[13] Kellerman, E. (1979). Transfer and non-transfer: Where we are now. Studies in Second Language Acquisition, 2, 37-57.

[14] Kellerman, E. (1983) . Now you see it, now you don't. In S. Gass, \& L. Selinker (eds.), Language transfer in language learning. Rowley, MA: Newbury House.

[15] Lennon, P. (1998). Approaches to the teaching of idiomatic language. IRAL, XXXVI (1), 11-30.

[16] Liontas, J. I. (2001). That's all Greek to me! The comprehension and interpretation of modern Greek phrasal idioms. The Reading Matrix, 1(1), 1-31.

[17] Liontas, J. I. (2002). Context and idiom understanding in second languages. EUROSLA Yearbook, 2, 155-185.

[18] Matlock, T., \& Heredia, R.R. (2002). Understanding phrasal verbs in monolinguals and bilinguals. In Heredia, R.R., \& Altarriba, J., (Eds.), Bilingual sentence processing. Elsevier, 251-274

[19] McCarthy, M. \& O'Dell, F. (2002). English idioms in use. Cambridge: Cambridge University Press.

[20] McDevitt, E. (1993). What does that mean? An introduction to American idioms. Department of Education, Washington, DC.

[21] Moon, R. (1997). Vocabulary connections: Multi-word items in English. In N. Schmitt \& M. McCarthy (eds.), Vocabulary: Description, acquisition and pedagogy. Cambridge: Cambridge University Press, 237-257

[22] Nelson, E. (1992). Memory for metaphor by nonfluent bilinguals. Journal of Psycholinguistic Research, 21, 111-125.

[23] Nunberg, G. (1978). The pragmatics of reference. Berkeley, CA: Indiana University Linguistics Club. 
[24] Prodromou, L. (2003). The idiomatic paradox and English as a lingua franca: Developing an idiomatic common core. Modern English Teacher, 12, 22-29.

[25] Saberian, N. (2011).The effect of idiom type and individual differences on idiom comprehension and strategy use of EFL students. Unpublished MA thesis, Islamic Azad University, Najafabad.

[26] Titone, D. A. \& Connine, C. M. (1994). Descriptive norms for 171 idiomatic expressions: Familiarity, compositionality, predictability, and literality. Metaphor and Symbolic Activity, 9, 247-70.

[27] Titone, D. A. \& Connine, C. M. (1999).On the compositional and non compositional nature of idiomatic expression. Journal of Pragmatics, 31, 1655-1674.

[28] Yoshikawa, H. (2008). International intelligibility in world Englishes: focusing on idiomatic expressions. International Communication Studies, XVII (4), 219-226.

Noorolhoda Saberian received her M.A in TEFL from Islamic Azad University, Najafabad Branch. Her areas of interest are psycholinguistics, research methodologies, syllabus design and second language acquisition.

Zahra Fotovatnia has a Ph. D in TEFL from Islamic Azad University, Science and Research Branch. She is an assistant professor at the English department of Islamic Azad University, Najafabad Branch. She has presented and published papers in international conferences and journals. 